\title{
A bibliometric review on nutrition of the exercising horse from 1970 to 2010
}

\author{
A. Jansson ${ }^{1,2}$ and P.A. Harris ${ }^{3}$ \\ 'Swedish University of Agricultural Sciences, Department of Animal Nutrition and Management, P.O. Box 7024, 75007 Uppsala, Sweden; \\ ${ }^{2}$ Holar University College, 551 Sauðárkrókur, Iceland, ${ }^{3}$ Equine Studies Group, WALTHAM Centre for Pet Nutrition, Freeby Lane, Waltham on \\ the Wolds LE14 4RT, United Kingdom; anna.jansson@slu.se; annaj@holar.is
}

Received: 26 June 2013 / Accepted: 3 September 2013

REVIEW PAPER

(c) 2013 Wageningen Academic Publishers

\begin{abstract}
The main aims of the present review are to provide a bibliometric analysis of the research published on the nutrition of the exercising horse from 1970 to 2010 and to determine whether this research has had any practical impact on feeding practices. In addition, we evaluated whether some of the key nutritional questions posed at the beginning of the 1980s have in fact been answered. Less than 300 publications were published in the period 1970-1980, but a large increase in the number of publications was observed between the period 1981-1990 and the period 19912000. Most papers were published in the Equine Veterinary Journal and American researchers, universities or institutes were particularly productive. The majority of the publications were in the areas of fluid balance, fat and glucose metabolism. Using information from field studies, there appears to have been a trend for a reduction in the amount of starch rich concentrates fed to performance horses from 1979 to 2007 and an increase in the use of oil supplementation. Whilst there have been several significant advances in our scientific knowledge of nutritional practices over the past few decades that have become routine practice in the field, others have not cascaded down. Unfortunately, we have not really fully answered any of the questions posed in the early 1980s and whilst it is possible that such questions can never be fully answered, there is also a concern that lack of sufficient funding, especially for the fundamental pieces of information needed to underpin our nutrition advice, will hamper progress in the future.
\end{abstract}

Keywords: diet, feed, performance, publication, training

\section{Introduction}

In the review on nutritional requirements of the exercising horse in the first proceedings of the International Conference on Equine Exercise Physiology (ICEEP) in 1983, Professor Harold Hintz noted that nutrition of the performance horse had received little attention from researchers over the previous few years. Through looking at world wide databases (Scopus and CAB Abstracts in March 2010) we can confirm this conclusion, as they show that less than 300 publications related to nutrition of the exercising horse were published in the period 1970-1980. From this point however, the publication rate increased and in fact roughly doubled in each of the following two decades. There are probably several reasons behind this expansion, including the increase in the use of the horse for leisure/pleasure purposes over this time and the demand for increased knowledge on how best to feed such animals. The main aims of the present review were to provide a bibliometric analysis of the research published on the nutrition of the exercising horse from 1970 to 2010 and to determine whether this research has had any practical impact on feeding practices. In addition, we aimed to evaluate whether some of the key nutritional questions posed in 1983 have in fact been answered.

\section{Bibliometry}

\section{Topics}

A bibliometric analysis was performed on publications related to nutrition of the exercising horse found in two world-wide data bases: CAB Abstracts and Scopus. The analysis included publications from 1970 to 2010 and the 
analyses were executed on the $5^{\text {th }}$ and $8^{\text {th }}$ of March 2010 (Cab Abstracts and Scopus, respectively). First, a basic search profile in titles, abstract and keywords was executed including three words (topics): horse, exercise, nutrition and words related and synonymous to these (Table 1). After this, sub-search profiles reflecting topics like forage, fibre, fat, protein, amino acid, electrolytes, minerals, glucose, glycogen, insulin sensitivity and time of feeding were added, one at a time (Table 1$)$.

Overall, the number of publications identified was smaller in Scopus compared to CAB (Table 1). This is due primarily to the different literature sources that each data base uses i.e. Scopus includes articles, articles in review, articles in press, reviews, conference papers, letters, editorials and notes, whereas $C A B$ Abstracts include journal articles as well as books, book chapters, miscellaneous, theses, abstracts only, conference proceedings, journal issues, annual reports, bulletin articles and correspondences. The results show that most publications were found in the areas of fluid balance, fat and glucose metabolism (Table 1). This most likely reflects the increased focus in the 1990s on mitigating any potential adverse effects of exercising under conditions of heat and humidity associated with the Atlanta Olympics (Jeffcott and Kohn, 1999), plus the increased popularity of endurance riding coupled with increasing awareness of the potential adverse effects of excessive grain intake (Kronfeld and Harris, 2003) which led to an increased interest in fat

Table 1. Publications from 1970-2010 related to nutrition of the exercising horse. The results are obtained from Cab Abstracts (5 March 2010) and Scopus database (8 March 2010). A basic (B) search profile was made and then a sub-search profile was added, one at a time.

\begin{tabular}{|c|c|c|c|c|c|c|c|c|c|c|c|c|c|}
\hline & \multirow[t]{2}{*}{ B } & \multicolumn{12}{|c|}{ Sub-search profiles within the basic } \\
\hline & & 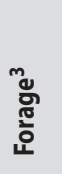 & 产 & 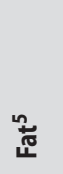 & 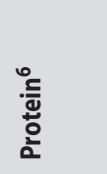 &  & 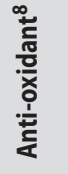 & 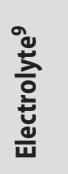 & 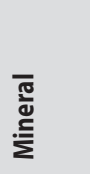 &  & $\begin{array}{l}\stackrel{\Xi}{0} \\
\text { ํㅡㄴ }\end{array}$ & 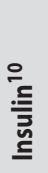 & 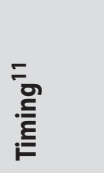 \\
\hline \multicolumn{14}{|l|}{$C A B^{1}$} \\
\hline 1970-1980 & 336 & 24 & $11 / 0$ & 50 & $50 / 1$ & 13 & 12 & 38 & 11 & 9 & 39 & 0 & 11 \\
\hline $1981-1990$ & 591 & 11 & $39 / 0$ & 46 & $47 / 3$ & 13 & 8 & 43 & 10 & 30 & 38 & 1 & 7 \\
\hline $1991-2000$ & 1,271 & 65 & $66 / 3$ & 133 & $124 / 10$ & 22 & 32 & 174 & $46^{12}$ & 36 & 90 & 1 & 27 \\
\hline 2001-2010 & 1,493 & 117 & $87 / 2$ & 202 & $174 / 11$ & 44 & 92 & 207 & $87^{13}$ & 58 & 147 & 23 & 77 \\
\hline Total & 3,691 & 217 & $203 / 5$ & 431 & $395 / 25$ & 92 & 144 & 462 & 154 & 133 & 314 & 25 & 122 \\
\hline \multicolumn{14}{|l|}{ Scopus ${ }^{2}$} \\
\hline $1970-1980$ & 27 & 2 & $0 / 0$ & 2 & $3 / 0$ & 1 & 5 & 5 & 1 & 2 & 5 & 0 & 2 \\
\hline $1981-1990$ & 62 & 12 & $0 / 0$ & 5 & $17 / 5$ & 0 & 5 & 18 & 2 & 5 & 9 & 0 & 13 \\
\hline $1991-2000$ & 214 & 49 & $8 / 4$ & 57 & $63 / 5$ & 15 & 26 & 90 & $25^{14}$ & 28 & 52 & 7 & 36 \\
\hline $2001-2010$ & 325 & 120 & $17 / 3$ & 93 & $102 / 9$ & 32 & 48 & 123 & $32^{15}$ & 49 & 92 & 34 & 97 \\
\hline Total & 628 & 183 & $25 / 7$ & 157 & $185 / 19$ & 48 & 84 & 236 & 60 & 84 & 158 & 41 & 148 \\
\hline \multicolumn{14}{|c|}{$\begin{array}{l}{ }^{1} \text { Topic }=(\text { horse OR horses OR foal* OR stallion* OR mare* OR equine OR equines OR yearling*) AND Topic=(exercise* OR'physical activity*' OR conditioning } \\
\text { OR training*) AND Topic=(diet* OR feed* OR intake OR supplement* OR oral OR nutrition). }\end{array}$} \\
\hline \multicolumn{14}{|c|}{$\begin{array}{l}{ }^{2}(\text { (horse OR horses OR foal OR stallion OR mare OR equine OR yearling) AND (exercise* OR'physical activity*' OR conditioning OR training) AND (diet* OR } \\
\text { feed* OR intake OR supplement* OR oral OR nutrition)) in article title, abstract or keywords. }\end{array}$} \\
\hline \multicolumn{14}{|c|}{${ }^{3}$ Full search: Forage* OR roughage* OR hay* OR haylage* OR silage* OR grass*. } \\
\hline \multicolumn{14}{|c|}{${ }^{4}$ Fibre* OR fiber*/Soluble fibre* OR Soluble fiber*. } \\
\hline \multicolumn{14}{|c|}{${ }^{5}$ Fat* OR oil* OR fatty acid*. } \\
\hline \multicolumn{14}{|c|}{${ }^{6}$ Protein* OR crude protein*/crude protein*. } \\
\hline \multicolumn{14}{|c|}{${ }^{7}$ Amino acid* OR aminoacid* OR lysine* OR tr } \\
\hline \multicolumn{14}{|c|}{${ }^{8}$ Antioxidant* OR vitamin*. } \\
\hline \multicolumn{14}{|c|}{${ }^{9}$ Electrolyte* OR sodium OR salt OR saline OR water. } \\
\hline \multicolumn{14}{|c|}{${ }^{10}$ Insulin sensitivity OR glycaemic* OR insulinaemic*. } \\
\hline \multicolumn{14}{|c|}{${ }^{11}$ Time of feed* OR timing*. } \\
\hline \multicolumn{14}{|c|}{${ }^{12} \mathrm{~A}$ search on calcium and phosphorus* resulted in 53 publications. } \\
\hline \multicolumn{14}{|c|}{${ }^{13} \mathrm{~A}$ search on calcium and phosphorus* resulted in 64 publications. } \\
\hline \multicolumn{14}{|c|}{${ }^{14}$ A search on calcium and phosphorus* resulted in 2 publications. } \\
\hline${ }^{15} \mathrm{~A}$ search on $\mathrm{Ca}$ & ium and & nospl & $5^{*}$ resulte & & cation. & & & & & & & & \\
\hline
\end{tabular}


supplementation. The surge in papers concerning glucose probably occurred due to an interest in the importance of glucose metabolism for performance and most likely also due to the proposed link between insulin resistance, obesity and laminitis (Coffman and Colles, 1983; Jeffcott et al., 1986). The latter may also have cascaded down from the increasing concern in human medicine with respect to the emerging obesity/diabetes epidemic and awareness of the importance of the 'metabolic syndrome.' The explosion of work in this area in humans started with the description by GM Reaven in the 1980s (Reaven, 1988) although the clustering of key factors had been noted before (see Sarafidis and Nilsson, 2006).

Many publications were also found using search topics 'forage, roughage, hay ..., 'fibre/fiber' and 'protein, crude protein' (Table 1). However, on closer inspection, these profiles tend to be very unspecific and include many publications where the dietary aspect was not in fact the primary focus of the publication. If the search profiles are limited to 'soluble fibre/fiber' or 'crude protein' the number of publications is in fact very small (5-25). However, the number of publications on 'amino acids, etc'. is almost 100 with an increasing trend over the years (Table 1). This may reflect increasing interest over this time period in amino acids within the human sport nutrition field (Blomstrand et al., 1991; Kreider et al., 1993) which then cascaded down to the equine.

Interestingly, the basic search profile loses more than $90 \%$ of the publications in both CAB and Scopus if the topic 'fatigue' is added, indicating that studies designed to evaluate nutritional impact on maximal performance are scarce, perhaps due to the difficulties in assessing such an impact or the fact that performance enhancing products are not allowed to be administered under Fédération Equestre Internationale or Jockey Club rules.

\section{Time effects on publication}

The basic search profile and almost all sub-search profiles executed in Cab Abstracts show the largest increase in the number of publications from the period 1981-1990 to the period 1991-2000 (Table 1). This could reflect society's increased interest in horses over this period. In many western countries the number of horses decreased after the Second World War and reached a minimum around 1970. From then, until at least the early part of the $21^{\text {st }}$ century and the recent economic downturn, the number of horses increased. In Sweden, for example, the number of horses increased more than 4-fold from 1970 to 2010 (Stark and Collman, 2012).
Two key search profiles, 'glycogen' and 'insulin sensitivity', however, do not show the largest increase from 1981 to 2000 in Cab Abstracts. In 1974, Lindholm and Piehl described the muscle biopsy technique in athletic horses which made studies looking at muscle glycogen possible and therefore led to the greatest increase in papers on glycogen from the period 1970-1980 to the period 1981-1990 (Table 1). Some of the main reasons behind the large increase in publications on 'insulin sensitivity' during 2001-2010 have been discussed previously. In addition, the availability of tests, adapted from work in humans, to assess insulin sensitivity in more detail (Hoffman et al., 2003) enabled studies to be undertaken in this area.

\section{Publishing journals, affiliations and authors}

Using the Scopus database, information on the number of journals and authors (and their affiliation) publishing in a specific search profile can be quantified. Most publications related to nutrition of the exercising horse during the last 40 years have been published in the Equine Veterinary Journal. However, the Journal of Equine Veterinary Science and Journal of Animal Science also published many manuscripts (Table 2). American researchers, universities or institutes overall have been most productive (Table 3 and 4). David Kronfeld and Patricia Harris were individually the most prolific publishing researchers in this area during this time. It is interesting to note that most of the top ten publishing researchers during 1970-2010 are still active today.

Table 2. Top ten journals with respect to number of publications from 1970-2010 on research related to nutrition of the exercising horse ${ }^{1}$. The results are obtained from the Scopus database (8 March 2010).

$\begin{array}{ll}\text { Journal } & \text { Pu } \\ & \\ \text { Equine Veterinary Journal Supplement } & 78 \\ \text { Equine Veterinary Journal } & 49 \\ \text { Journal of Equine Veterinary Science } & 39 \\ \text { Journal of Animal Science } & 39 \\ \text { Veterinary Clinics of North America Equine Practice } & 27 \\ \text { Veterinary Journal } & 22 \\ \text { Journal of the American Veterinary Medical Association } & 21 \\ \text { American Journal of Veterinary Research } & 21 \\ \text { Journal of Nutrition } & 17 \\ \text { Pferdeheilkunde } & 13\end{array}$

${ }^{1}$ Search profile: ((horse OR horses OR foal OR stallion OR mare OR equine OR yearling*) AND (exercise* OR 'physical activit*' OR conditioning OR training) AND (diet* OR feed* OR intake OR supplement* OR oral OR nutrition)) in article title, abstract or keywords. 
Table 3. Top eleven authors with respect to number of publications from 1970-2010 on research related to nutrition of the exercising horse ${ }^{1}$. The results are obtained from the Scopus database ( 8 March 2010).

\begin{tabular}{ll} 
Author and country & Publications \\
Kronfeld, D.S., USA & 31 \\
Harris, P.A., United Kingdom ${ }^{2}$ & 30 \\
Geor, R.J., USA & 19 \\
Valberg, S.J., USA & 17 \\
Lawrence, L.M., USA & 14 \\
Pagan, J.D., USA & 14 \\
Hinchcliff, K.W., USA & 12 \\
Coenen, M, Germany & 11 \\
Jansson, A., Sweden & 10 \\
Rose, R.J., Australia & 10 \\
Potter, G.D., USA & 10 \\
\hline & \\
\hline & 'Search profile: ((horse OR horses OR foal OR stallion OR mare OR equine \\
OR yearling*) AND (exercise* OR 'physical activit' OR conditioning OR \\
training) AND (diet* OR feed* OR intake OR supplement* OR oral OR \\
nutrition)) in article title, abstract or keywords. \\
${ }^{2}$ Another 7 publications can be found with author: Harris, P.
\end{tabular}

\section{Have some of yesterday's expectations been fulfilled?}

The following is a non-exhaustive review of a few key nutritional questions posed in 1983 and some of the subsequent published research that has tried to answer them.

\section{Energy requirements and body condition}

Apart from the conclusion that there was a general lack of information with respect to the nutrition of the athletic horse in his 1983 ICEEP review, Professor Hintz also highlighted some specific nutritional questions that he thought needed to be answered. Hintz suspected for example that the energy requirement suggested by the American National Research Council (NRC) 1973-1978 for high intensity exercise was too low (24-39 kcal/h/ kg body weight (BW)). This was most likely based on his own findings in surveys of Standardbred horses in training (Ignatoff and Hintz, 1980; Nash and Hintz, 1981). His view has subsequently been confirmed in several other field studies (Glade, 1983; Southwood et al., 1993; Zmija, 1991). In the NRC issues from both 1989 and 2007, the daily digestible energy (DE) requirements for $500 \mathrm{~kg}$ horses in training/ performing very heavy exercise is suggested to be around 34 Mcal which corresponds to $120-180 \%$ of the requirement suggested in 1973.
Table 4. Top ten affiliations with respect to number of publications from 1970-2010 on research related to nutrition of the exercising horse ${ }^{1}$. The results are obtained from the Scopus database $(8$ March 2010).

$\begin{array}{lc}\text { Affiliation, country } & \text { Pu } \\ \text { Virginia Polytechnic Institute and State University, USA } & 26 \\ \text { WALTHAM Centre for Pet Nutrition, United Kingdom } & 23 \\ \text { Swedish University of Agricultural Sciences, Sweden } & 18 \\ \text { Animal Health Trust, United Kingdom } & 17 \\ \text { Michigan State University, USA } & 16 \\ \text { University of Sydney; Australia } & 14 \\ \text { Texas A and M University, USA } & 15 \\ \text { Ohio State University, USA } & 14 \\ \text { University of Minnesota Twin Cities, USA } & 14 \\ \text { Utrecht University, the Netherlands } & 13\end{array}$

${ }^{1}$ Search profile: ((horse OR horses OR foal OR stallion OR mare OR equine OR yearling*) AND (exercise* OR 'physical activit*' OR conditioning OR training) AND (diet* OR feed* OR intake OR supplement* OR oral OR nutrition)) in article title, abstract or keywords.

${ }^{2}$ Often described by the Swedish name, another 4 publications can be found in English including an old faculty name.

Hintz also concluded that studies were needed to determine 'optimum body condition for optimal performance'. Around the time of his comment Henneke et al. (1983) published a more objective 9 point body condition scoring system originally described for assessing pregnant quarter horse mares but which has been used globally in numerous studies in all types of animals. However, until recently this had not been validated fully in the horse. Validation was needed however, especially with the increased focus on obesity and drivers of weight gain and weight loss (Dugdale et al., 2011a,b, 2012). Recent work on body condition has concentrated more on weight gain/weight loss and the clinical consequences of obesity (Geor and Harris, 2009, 2013) rather than its effect on optimal performance in a competitive context. That body fat content is inversely related to both sprint and endurance running performance in humans has been known for more than 20 years (Barnard et al., 1979; Thorland et al., 1987). In 1992, Lawrence et al. (1992) showed that the most competitive horses in a 150-mile endurance race (finishers in the top 7) had lower body condition scores and less rump fat than noncompetitive horses eliminated for metabolic causes. In elite Standardbred horses, a strong positive relation was observed between race time and estimated percentage of body fat in stallions (Kearns et al., 2002). In that study, the one mile race time increased with approximately 1 second for every estimated percentage of increase in body fat. In French trotters a negative correlation between body condition scores/fat mass and $\mathrm{V}_{4}$ has been observed (Leleu and Cotrel, 2006), which in turn has been correlated to 
performance in the same population of horses (Leleu et al., 2005). Despite all of this work relatively little has been published with respect to the original question posed by Hintz. In fact the relationship between body fatness, fatfree mass and running performance has not been studied in great detail in the horse, unlike man. It has, however, been stated that the optimal bodyweight of racehorses has a high correlation with performance (Lim, 1980) and that the optimal bodyweight for a racehorse has a range of only $\pm 1.5 \%$. Lawrence et al. (1992) and Kearns et al. (2002) suggest that the performance reduction related to increased body condition is due to an increased weight load (approximately 20 and $30 \mathrm{~kg}$ in the endurance and Standardbred study, respectively). Obviously the amount of energy needed to run is related to the weight being moved and an increase in bodyweight therefore increases the cost of locomotion. It has been shown that the addition of a $10 \%$ load to horses exercising on a horizontal treadmill increased $\mathrm{O}_{2}$ consumption by $15 \%$ (Garlinghouse and Burrill, 1999) and also that an acute reduction in bodyweight following administration of furosemide resulted in decreased anaerobic energy expenditure during brief high-intensity work, which may be the reason for any postulated improvement in performance (Hinchcliff, 1999). Gut fill also affects bodyweight and the metabolic response to exercise. A restricted hay intake (for 3 days at $1 \% \mathrm{BW}$ ) compared to ad libitum feeding resulted in a decrease of approximately $2 \%$ in BW and an increase in the mass specific rate of oxygen consumption during sprint exercise with a corresponding decrease in anaerobic energy expenditure (Rice et al., 2001).

\section{Fluid and electrolyte requirements}

In the 1983 issue of ICEEP, Gary Carlson concluded that there 'remain substantial gaps in our knowledge' regarding fluid and electrolyte balance and that there were very few data on the response to orally administered fluids. In spite of that, he suggested that in most racing situations, the provision of free-choice trace-mineralized salt along with a balanced ration should provide all the electrolytes necessary for full performance. Twenty-seven years later, no one has challenged this statement by studying true performance during free-choice availability of sodium. However, there is at least one study indicating that Standardbred horses in training with ad libitum access to a salt block, will have a sodium intake below their expected requirements and a reduced plasma volume (Jansson and Dahlborn, 1999). In contrast, there are studies which suggest that free choice access might be sufficient for those in little or no work (Schryver et al., 1987). There are also experimental studies which show that sodium deprivation reduces feed and water intake, plasma volume and sweating rate, plus it alters exercise associated fluid shifts and increases packed cell volume (Jansson et al., 2010; Lindner et al., 1983; Meyer 1987). Another study has shown that oral fluid and electrolyte administration in connection with exercise improves the maintenance of plasma volume (Geor and McCutcheon, 1998). Altogether this suggests that providing an adequate sodium and fluid intake is important for the exercising horse and that, in contrast to what was suggested by Carlson in 1983, free choice salt provision cannot generally be recommended for high performance horses. However, the question that has been posed more recently is what exactly are the optimal recommendations for salt provision. Over the last few decades recommendations have ranged from trying to replace (through feed supplementation/oral dosing/strategic use of salt water) all or most of the sodium lost in the sweat based on changes in bodyweight or postulated energy expenditure (GfE, 1994; NRC, 2007) to concerns that such levels of salt supplementation either may not be required (Harris and Schott, 2013) or may actually result in a mild metabolic acidosis at least in animals in moderate work on low hay rations (Romanowski et al., 2009). This debate promises to continue through published work and evidence based medicine over the next few decades.

\section{Pre-race nutrition and true performance}

At a workshop (Horse Nutrition Symposium) held in Uppsala (Sweden) in 1983, with participants from both universities and the horse industry, it was concluded that a future research task was to study how horses should be fed in the immediate time period (rather than in the weeks/ months) before a race, with respect to glucose and glycogen in blood and muscle respectively. Whilst 20 years later there are several publications on the response of feeding prior to exercise on some plasma variables and muscle glycogen values (e.g. Duren et al., 1999; Pagan and Harris, 1999) there have been no studies to the authors' knowledge on true performance (races). The lack of such studies is probably due to practical and economic constraints. Unless the effect of diet is dramatic (i.e. starved, obese or dehydrated animals), the effect on performance may be difficult to measure in real races since race results are influenced by many other variables not responsive to changes in the diet (e.g. rider, ground conditions, fitness of the horse, position in the race, etc.). The time difference between the first and last healthy horse (from different stables and on diets) finishing harness or flat races is often only a few seconds which makes minor treatment effects difficult to detect during field conditions. Evaluation of the effect of diet on race performance, therefore, needs to be done on a very large number of observations or in experimental races, which has not so far taken place. Although, a few research endurance rides have been undertaken in which different basal diets and electrolyte supplements have been fed (Hess et al., 2005; Nyman et al., 1996; Williams et al., 2004). During the time period covered by this review high speed treadmills became popular as a means to evaluate changes in response to exercise at different intensities. It could be argued that data evaluating the effect of dietary 
interventions on treadmill performance, could then be used to indicate the likely response in the field under actual race conditions. However, such studies are also very expensive and the actual effects on certain key parameters may be so small as to be masked by the normal withinsubject variability intrinsic to any testing program as well as the sensitivity of the procedures employed. Such small changes, however, in an actual competition, could make the difference between winning or being placed. Alternatively, treadmill based studies could show a statistically significant effect of a compound or element on some physiological or biochemical function, which, in the field, is not manifest in any significant improvement in performance. This highlights a major issue - other than in actual competitions or races how can you access performance (and across all the different disciplines)? Dose response and timing effects are other key factors that need to be taken into account and a lack of response may just reflect an inappropriate dose or timing interval rather than lack of any potential to have a benefit.

Regardless, there is evidence from several studies that the timing and composition of a meal consumed before exercise is likely to influence the metabolic response during competition (Harris and Graham-Theirs, 1999; Lawrence et al., 1993, 1995; Pagan and Harris, 1999; Stull and Rodiek, 1995). An illustration of this can be seen in Figure 1. In particular, the hyperglycaemia and insulinaemia associated with the digestion and absorption of grain meals affects the mix of substrates utilised during a bout of exercise. Insulin is a potent inhibitor of lipolysis and fatty acid oxidation in skeletal muscle, and also promotes glucose uptake into muscle via recruitment of the transporter protein GLUT4 to the sarcolemma. Thus, hyperinsulinemia at exercise onset will suppress non-esterified fatty acid (NEFA) availability as well as lipid oxidation and increase reliance on carbohydrate stores (including plasma glucose) for energy transduction. The decrease in plasma glucose that occurs when horses are exercised 2-3 hours post a grain meal tends to be relatively short term. However, plasma NEFA and lipid oxidation may remain lower in fed animals when compared to the fasted state throughout certain types of more long term exercise (Jose-Cunilleras et al., 2002). These changes may not be relevant in the extreme sprinting racehorse, which does not rely on plasma NEFA as an energy source but obviously could be a factor in longer races.

When we look at the effect of the core diet on true performance in actual competitions there are only a small number of published studies, with a few more that show effects of nutrition on experimental exercise performance. As mentioned earlier, two studies indicated that body condition (and therefore energy intake) would affect Standardbred and endurance race performance (Kearns et al., 2002; Lawrence et al., 1992). In addition, Glade (1983) suggested that high crude protein (CP) intakes would increase race times in Thoroughbreds (average times to finish increased by 1 to $3 \mathrm{sec}$, depending on the race distances, for every $1000 \mathrm{~g}$ of $\mathrm{CP}$ ingested in excess of NRC recommendations of that time). Although a reduced performance could be a logical conclusion as high protein intakes cause increased heat and hydrogen production, factors that, at least theoretically, can be a challenge to exercise performance, the study by Glade had some confounding factors and further studies are needed to confirm or refute this suggested effect on performance. Graham-Thiers et al. (2001) showed that venous pH was higher during treadmill sprint exercise in horses fed a low protein diet. In another study comparing two forageonly diets, one providing recommended (NRC, 2007) CP intake and another providing $160 \%$ of the $\mathrm{CP}$ requirement, venous $\mathrm{pH}$ during Standardbred race-like exercise was not significantly affected by diet but estimated heat and evaporative losses at rest was higher on the high CP diet (Connysson et al., 2006). Again, whether such effects will be clinically significant in practice has not been evaluated in depth and further work is needed in this area.

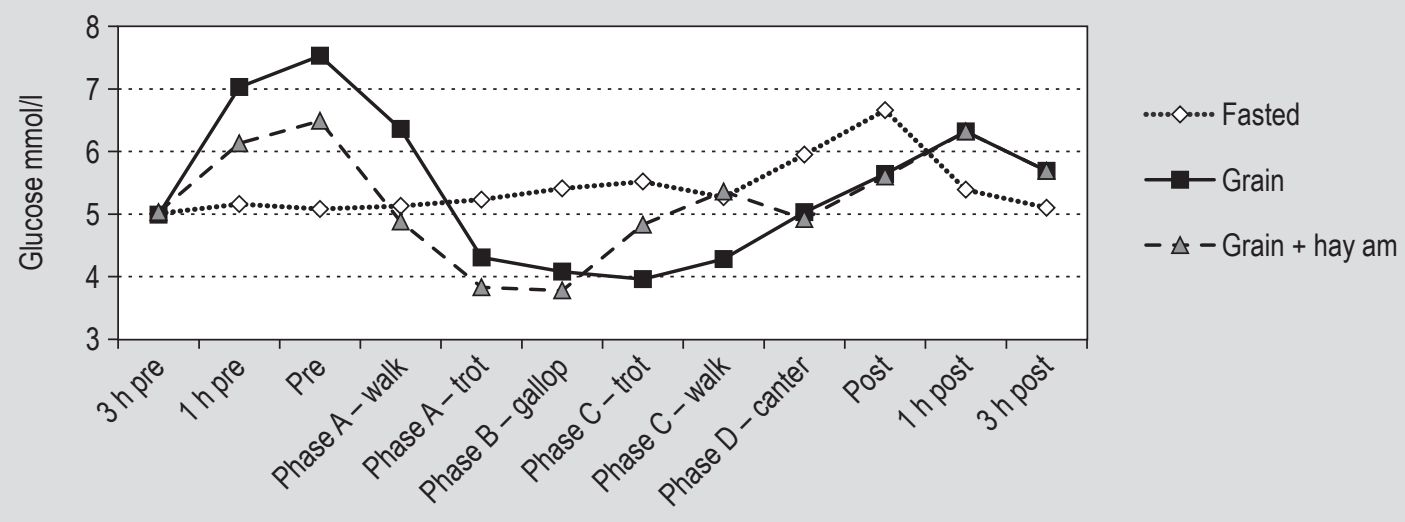

Figure 1. Plasma glucose concentrations before, during and after a standardised exercise test (Pagan and Harris 1999). 


\section{Diet and performance}

The increased interest in fat/oil supplementation probably developed, at least in part, as a result of work in the mid1970s which suggested that horses fed a diet containing 12\% fat (9\% added corn oil), and ridden $67 \mathrm{~km}$ over mountainous terrain for 8-10 hours, performed better and had higher blood glucose levels at the end of the ride than horses fed the control diet (3\% fat) (Slade et al., 1975). Two subsequent field studies showed improved speed or race times in horses on fat supplemented diets. Harkins et al. (1992) observed improved race times over $1,600 \mathrm{~m}$ following fat supplementation (12\% dietary fat). However, this study could have been confounded by training effects. Oldham et al. (1990) observed horses, fed 0 and $10 \%$ supplementary fat in a switch back design, performing four $600 \mathrm{~m}$ gallops. Fat supplemented horses had higher pre-exercise muscle glycogen contents and galloped faster at a constant heart rate during the last 2 gallops. It was concluded that adapting exercising horses to a fat-supplemented diet increased muscle glycogen concentrations and appeared to improve performance above the anaerobic threshold. Lacombe et al. (1999) showed that reduced muscle glycogen content impairs endurance during high intensity exercise and Snow et al. (1981) observed that the horse with the lowest muscle glycogen content prior to an endurance race was eliminated early. However, in the study by Lacombe et al. (2001) the glycogen reduction (90\%) was obtained by exercise. Several studies have suggested that fat/oil supplemented diets have an effect on glycogen utilization and some have suggested a sparing or enhancing glycogen storage effect (see Harris, 1997). Pagan et al. (2002) showed that fat supplementation ( 29 vs. $7 \%$ of daily DE intake) reduces the estimated level of whole-body carbohydrate utilisation. However, the effect of fat/oil supplementation on muscle glycogen content is disputed (Waller and Lindinger, 2010). Fat supplemented diets have in fact been suggested to lower or to have no effect on pre-exercise muscle glycogen content and to have no effect on glycogen utilization or post exercise muscle glycogen content (Geor, 2013). It is important, however, to note that the relative proportions of the different energy sources used in the ration of competition horses can have other effects that might influence performance, irrespective of any effect on muscle glycogen content. These include effects on behaviour, gut health in general and gastric ulceration in particular - all of which may influence performance, but cannot be covered here.

Two experimental studies have shown that intravenous administration of glucose during exercise increases the time to fatigue (Farris et al. 1998; Lacombe et al. 2001). From a practical, dietary perspective the importance of this finding is unclear. However, oral fluid administration (water or an isotonic electrolyte and glucose solution), after exercise induced sweat loss and prior to a second exercise bout at high environmental temperatures, was shown to reduce the increase in body temperature seen during exercise. In the un-supplemented group, one of the horses was unable to complete the exercise protocol due to fatigue (Geor and McCutcheon, 1998). More recently published work has suggested that the restoration of hydration and electrolyte/ acid-base balance may be more important to glycogen re-synthesis than any additional glucose administration (Waller et al. 2009). Fluid supplementation appears therefore to be of importance for performance in general.

Over the time period of this review a few studies were undertaken with the aim of assessing glycogen repletion patterns in horses and the effect of diets of varying composition. These have shown only a small positive effect of adding starch to the diet (Jose-Cunilleras et al., 2006; Lacombe et al., 2004; Snow et al., 1987) on the rate of repletion. Perhaps the most striking finding has been that the rate of repletion is slow (compared to that in man), even in horses fed high amounts of glucose providing concentrates. The general opinion today, is that the rate of glycogen repletion post exercise can only be improved to a very limited extent by increasing the starch proportion of the diet (Harris et al., 2013) and other strategies may need to be employed. There is, for example, one study indicating that a high protein intake might increase muscle glycogen stores (Essén-Gustavsson et al., 2010) which is in accordance with observations in rats (De Araujo et al., 2006; Morifuji et al., 2005). The work in horses may, however, have been confounded as the NSC intake was also higher with the high protein diet.

\section{Has research had any practical relevance with respect to current feeding practices?}

\section{Review}

In order to try and answer this question a review of published field studies on feeding regimens in Thoroughbred and Standardbred race horses was conducted. The aim was to look for any trends or changes in the feeding regimens over time that could be linked back to published research.

In 1980, Ignatoff and Hintz published data on feed, energy and CP intake in 120 Standardbred horses in training at two American race tracks. They concluded, as mentioned above, that the NRC's (1978) estimates of energy requirements appeared to underestimate the needs of Standardbred race horses (fed $35 \mathrm{Mcal} \mathrm{DE} /$ day fed vs. $27 \mathrm{Mcal} \mathrm{DE} /$ day recommended) and that the average diet in the field provided more CP than recommended by NRC ( $1570 \mathrm{~g} /$ day vs. $585 \mathrm{~g}$ recommended). This finding that practically, horses were being fed more protein than recommended was supported by a number of observations. Mullen et al. (1979), for example, reported daily intakes of digestible CP greater than $1000 \mathrm{~g}$ in two year old British Thoroughbred horses and Glade (1983) observed CP intakes of 1,380 to 2,140 g/day in 
American Thoroughbred race horses. In the 1989 issue of the NRC recommendations, the $\mathrm{DE}$ and $\mathrm{CP}$ requirement of horses in heavy training was in fact increased to about 33 $\mathrm{Mcal} /$ day and 1,300 g/day, respectively for a $500 \mathrm{~kg}$ horse. The latter was based on observations of nitrogen retention in horses in training (Freeman et al., 1988) and nitrogen lost via sweat. A dietary digestible CP:DE ratio, sufficient for maintenance, was suggested to provide adequate amounts of protein across all workloads given that the total energy intake would be higher in working horses. Even though the NRC CP recommendation for race horses had been increased to1,300 g/day, the mean CP intake was even higher ( 2,100 g/day) in a field survey performed in 1992 in the USA (Gallagher et al., 1992). The apparent disregard for the suggestion by Glade in 1983 that protein intakes should be kept moderate might be for a number of reasons, including the fact that many trainers/veterinarians may not be aware of Glades' suggestions, or that practically his results are not valid and such high protein intakes are not detrimental in high performance animals with an adequate water supply and good ventilation, etc. It is also difficult to change traditional feeding strategies, especially those that are perceived to be of value. Alternatively, there may be some unknown advantages in providing such a level of protein intake (originally perhaps ensuring adequate essential amino acid intakes in cereal based rations).

Table 5 contains a review of field studies on feeding strategies used in Thorougbred and Standardbred training stables globally from 1979 to 2007. It shows that throughout this period various grass and legume hays, oats and mixed grains and commercial feeds were the major feedstuffs being fed. No statistical differences $(P>0.05)$ in feed allowances between Thoroughbred and Standardbred horses could be

Table 5. Forage and concentrate allowances ( $k g$ feed) and feed descriptions in Thoroughbred (TB) and Standardbred (SB) training stables in United Kingdom (UK), United States (USA), Germany, Australia, Sweden and New Zealand (NZ) from 1979 to 2007.

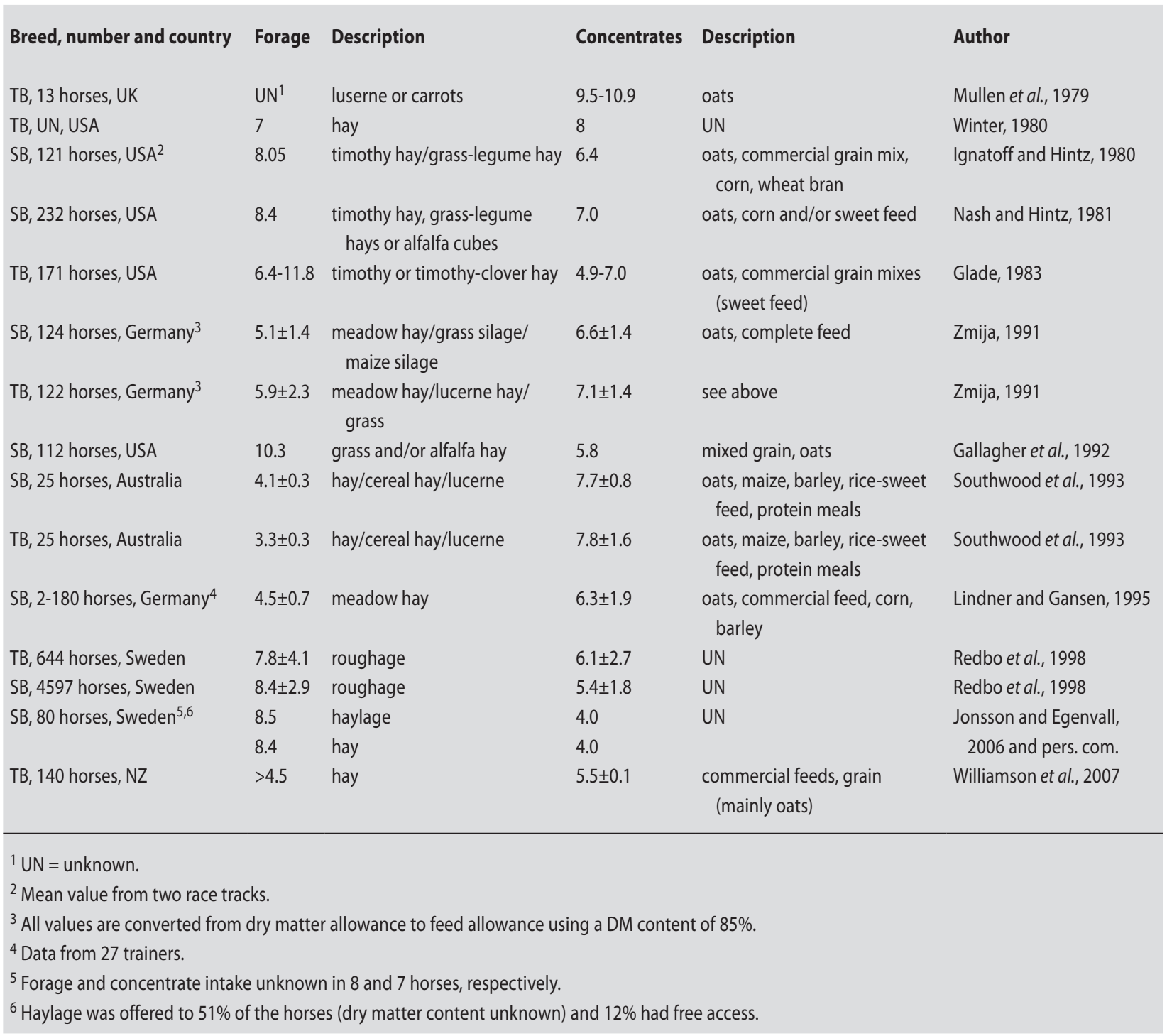


observed using this data (forage: $5.7 \pm 0.4$ vs. $5.8 \pm 0.4 \mathrm{~kg} /$ day and concentrate: $7.4 \pm 0.3$ vs. $6.8 \pm 0.4 \mathrm{~kg} /$ day (LS Means, analysis of variance including breed, time period and country in the model)), although single studies have suggested that Standardbreds are fed more roughage than Thoroughbreds (Southwood et al., 1993) and Thoroughbreds more energy providing complementary feedstuffs (concentrates) than Standardbreds (Redbo et al., 1998). A tendency $(P=0.06)$ for a higher forage allowance in the years 1991-2007 compared to $1979-1990$ was observed $(6.8 \pm 0.3$ vs. $4.8 \pm 0.8 \mathrm{~kg} /$ day $)$ but there was no difference in the concentrate allowance $(6.7 \pm 0.3$ vs. $7.5 \pm 0.6 \mathrm{~kg} /$ day $)$. However, using the same data as in Table 4 there is a trend for a reduction in the concentrate allowance over time (Figure 2). If we assume that the energy needs of Thoroughbred and Standardbred horses in training have not decreased over the years, this observation supports either that the forage allowance has increased or there has been an increase in the energy density of the feedstuffs used. An increased energy content of the forages used is possible, especially in countries where there is a trend for using haylage or silage instead of hay. Generally, haylage or silage can be harvested and stored at conditions promoting a higher nutritive value than hay, and silage has also been shown to have a higher digestibility than hay in horses in training (Muhonen et al., 2009). However, another more likely explanation is that the energy density of the concentrates being fed has increased, probably due to an increased inclusion of fat/oil. The market-leading horse feed company in Sweden (Krafft AB, Falkenberg, Sweden)), with business in 20 European countries, confirms that the oil content of their ordinary sport feeds has increased from $3 \%$ in 1970 to $5-6 \%$ in 2010 . Today, they also have high oil feeds (7-8.5\%) and are growing and selling a high-fat oat variety (9-10\% fat). Similar trends have been seen in the UK with an increase in the level of oil in typical performance feeds and the launch of high oil feeds ( $15 \%$ oil $)$ in the 1990s (MARS Horsecare, personal communication). An increase in the oil content of the concentrates from 3 to $6 \%$ (in exchange for oats) will increase the metabolisable energy content by approximately $1 \mathrm{MJ} / \mathrm{kg}$ feed and together with an increased forage allowance this could explain the findings illustrated in Figure 2, that the concentrate intake has decreased over the years.

Another change that has occurred over the last few decades, partly in response to published research and the desire to restrict starch intakes (in order to reduce the risk of behavioural issues/gastric ulceration and other gastrointestinal disturbances, as well as clinical issues such as recurrent exertional rhabdomyolysis) and yet provide sufficient energy for the competition horse, has been the increasing inclusion of so called highly digestible fibres or super fibres into the ration. Sugar beet pulp is one example of such a fibre source where the response to exercise has been studied and positive effects like decreased glycogen utilisation and lowered plasma lactate concentration have

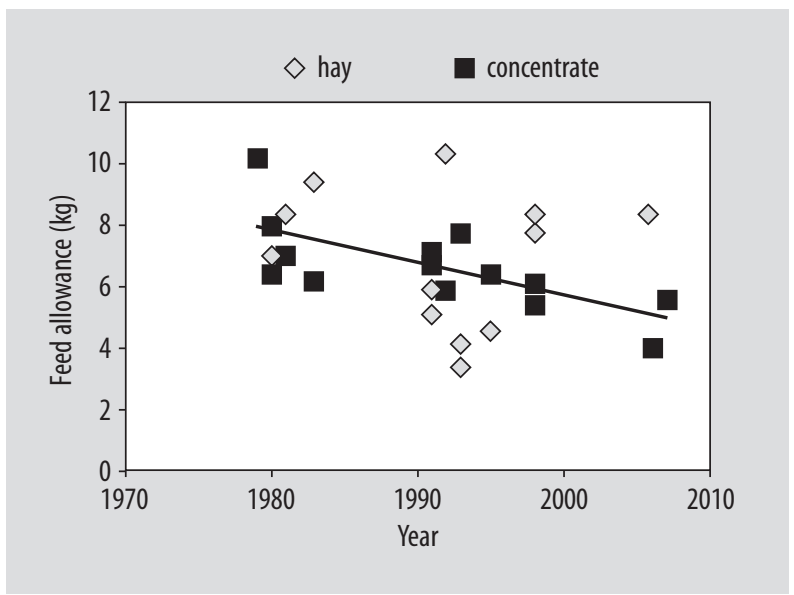

Figure 2. Daily hay and concentrate allowances reported in surveys performed in Thoroughbred and Standardbred training stables in six countries from 1979 to 2007 (for more information see Table 5). The regression line is fitted to the concentrate allowance. $Y=-$ $\left.0.1061 x+218.01, R^{2}=0.458, P=0.0056\right)$.

been suggested (Palmgren-Karlsson et al., 2002). It has also been suggested that sugar beet pulp practically provides more DE to the horse than its crude fibre, protein, fat, etc. analysis would suggest ( $20 \%$ more; Crandell et al., 1999; Pagan, 1997). This is supported by a study by Lindberg and Palmgren-Karlsson (2001) in which total fibre digestibility increased with increasing sugar beet pulp inclusion in the diet (at the expense of oats). This could be an effect of the high content of soluble and highly fermentable plant fibre carbohydrates in sugar beet pulp, which will be accounted for when the fibre content is expressed as total fibre, but which are only partly included in the neutral detergent and crude fibre analyses.

\section{Conclusions and future}

Feeding of horses is an art and a science - the published science provides either the trigger for changes in the art or changes in the art drive science to provide explanations. Over the past few decades there have been significant advances in our scientific knowledge of nutritional practices that have become routine practice in the field, but others that have not cascaded down for cost, practicality or just time reasons.

Looking to the future some of the most important nutrition questions that still need to be answered would perhaps be the same as those posed in 1983, although widened in their scope. For example rather than just considering how diet may influence muscle development and repair, we should consider how diet may affect the 'quality' of the locomotor apparatus in general - very crucial given that the locomotor system appears to be the main 'limiter' to improved performance (Dyson et al., 2008; Vigre et al., 2002). In addition, there has been recently an increasing 
use of so called 'supplements' or 'nutraceuticals' in both our own and our animal's diets. Diet is now seen not just as a means to provide the core nutrients required to support life but as a means to manage and help prevent certain clinical conditions and to prolong healthy life. This, therefore, is perhaps one of the biggest challenges going forward: to understand the potential benefits as well as the contraindications around nutrition in its broadest sense as it affects the short as well as long term health of the horses in our care. However, there is a major concern that lack of sufficient funding, especially for the fundamental pieces of information needed to underpin our nutrition advice going forward, will hamper progress in the future.

Finally, the increasing numbers of humans and their demand for food and energy also has the potential to either limit or make the traditional feedstuffs fed to horses too costly and alternatives are required. This is perhaps a pivotal point in the history of equine nutrition, and science should be leading the quest for sustainable food supplies for the horses in our care. It will be interesting to see what the next 3 decades bring.

\section{Acknowledgements}

The authors wish to acknowledge the tremendous debt they and equine nutrition research owe to Professor David Kronfeld who published extensively over the time period evaluated and who sadly died in 2007 . His vision, insight, knowledge, and challenging questions are missed.

\section{References}

Barnard, R.J., Grimditch, G.K. and Wilmore, J.H., 1979. Physiological characteristics of sprint and endurance Masters runners. Medicine and Science in Sports and Exercise 11: 167-171.

Blomstrand, E., Hassmen, P., Ekblom, B. and Newsholme, E.A., 1991. Administration of branched-chain amino acids during sustained exercise - effects on performance and on plasma concentration of some amino acids. European Journal of Applied Physiology and Occupational Physiology 63: 83-88.

Carlson, G., 1983. Thermoregulation, fluid and electrolyte balance. In: Snow, D.H., Persson, S.G.B. and Rose, R.J. (eds.) Equine exercise physiology 1. Granta Editions, Cambridge, UK, pp. 291-309.

Coffman, J.R. and Colles, C.M., 1983. Insulin tolerance in laminitic ponies. Canadian Journal of Comparative Medicine 47: 347-351.

Connysson, M., Muhonen, S., Lindberg, J.E., Essén-Gustavsson, B., Nyman, G., Nostell, K. and Jansson, A., 2006. Effects on exercise response, fluid and acid-base balance of protein intake from forageonly diets in Standardbred horses. Equine Veterinary Journal Suppl. 36: 648-653.

Crandell, K., Pagan, P., Harris, P. and Duren, S., 1999. A comparison of grain oil and beet pulp as energy sources for the exercised horse. Equine Veterinary Journal Suppl. 30: 485-490.
De Araujo Jr., J.A., Falavigna, G., Pires, I.S.O., Pedrosa, R.G., Castro, I.A., Donato Junior, J. and Tirapegui, J., 2006. Effect of chronic supplementation with branched-chain amino acids on the performance and hepatic and muscle glycogen content in trained rats. Life Sciences 79: 1343-1348.

Dugdale, A., Grove-white, D., Curtis, G.C., Harris, P. and Argo, C.M.C.G., 2012. Body condition scoring as a predictor of body fat in horses and ponies. Veterinary Journal 194: 173-178.

Dugdale, A.H.A., Curtis, G.C., Harris, P. and Argo, C.M., 2011a. Assessment of body fat in the pony: part I. Relationships between the anatomical distribution of adipose tissue, body composition and body condition. Equine Veterinary Journal 43: 552-561.

Dugdale, A.H.A., Curtis, G.C., Milne, E., Harris, P. and Argo, C.M., 2011b. Assessment of body fat in the pony: part II. Validation of the deuterium oxide dilution technique for the measurement of body fat. Equine Veterinary Journal 43: 562-570.

Duren, S.E., Pagan, J.D., Harris, P.A. and Crandell, K.G., 1999. Time of feeding and fat supplementation affect plasma concentrations of insulin and metabolites during exercise. Equine Veterinary Journal Suppl. 30: 479-484.

Dyson, P.K., Jackson, B.F., Pfeiffer, D.U. and Price, J.S., 2008. Days lost from training by two- and three-year-old Thoroughbred horses: a survey of seven UK training yards. Equine Veterinary Journal 40: 650-657.

Essén-Gustavsson, B., Connysson, M. and Jansson, A., 2010. Effects of crude protein intake from forage-only diets on muscle amino acids and glycogen levels in horses in training. Equine Veterinary Journal Suppl. 38: 341-346.

Freeman, D.W., Potter, G.D., Schelling, G.T. and Kreider, J.L., 1988. Nitrogen metabolism in mature horses at varying levels of work. Journal of Animal Science 66: 407-412.

Gallagher, K., Leech, J. and Stowe, H., 1992. Protein, energy, and dry matter consumption by racing Standardbreds: a field survey. Journal of Equine Veterinary Science 12: 382-388.

Garlinghouse, S.E. and Burrill, M.J., 1999. Relationship of body condition score to completion rate during $160 \mathrm{~km}$ endurance races. Equine Veterinary Journal Suppl. 30: 591-595.

Geor, R., 2013. Endocrine and metabolic physiology. In: Geor, R., Harris, P. and Coenen, M. (eds.) Equine applied and clinical nutrition. Saunders Elsevier, Philadelphia, PA, USA, pp.57.

Geor, R.J and McCutcheon, L.J, 1998. Hydration effects on physiological strain of horses during exercise-heat stress. Journal of Applied Physiology 84: 2042-2051.

Geor, R.J. and Harris, P., 2009. Dietary management of obesity and insulin resistance: countering risk for laminitis. In: Geor, R.J. (ed.) Veterinary clinics of North America (equine practice). Elsevier Saunders, Philadelphia, PA, USA, pp. 51-66.

Geor, R.J. and Harris, P.A., 2013. Obesity. In: Geor, R.J., Harris, P.A. and Coenen, M. (eds.) Equine clinical and applied nutrition. Elsevier Saunders, Philadelphia, PA, USA, pp. 487-502.

Gesellschaft für Ernährungsphysiologie (GfE), 1994. Empfehlungen zur Energie- und Nährstoffversorgung der Pferde. DLG Verlag, Frankfurt am Main, Germany.

Glade, M.J., 1983. Nutrition and performance of racing Thoroughbreds. Equine Veterinary Journal 15: 31-36. 
Graham-Thiers, P.M., Kronfeld, D.S., Kline, K.A. and Sklan, D.J., 2001. Dietary protein restriction and fat supplementation diminish the acidogenic effect of exercise during repeated sprints in horses. Journal of Nutrition 131: 1959-1964.

Harkins, J.D., Morris, G.S., Tulley, R.T., Nelson, A.G. and Kamerling, S.G., 1992. Effect of added dietary fat on racing performance in Thoroughbred horses. Journal of Equine Veterinary Science 12: 123-129.

Harris, P.A. and Graham-Thiers, P.M., 1999. To evaluate the influence that 'feeding state' may exert on metabolic and physiological responses to exercise. Equine Veterinary Journal Suppl. 30: 633-635.

Harris, P.A. and Schott, H.C., 2013. Nutritional Management of elite Endurance horses. In: Geor, R.J., Harris, P.A. and Coenen, M. (eds.) Equine clinical and applied nutrition. Saunders Elsevier, Philadelphia, PA, USA, pp. 272-288.

Harris, P.A., 1997. Energy requirements of the exercising horse. Annual Review of Nutrition 17: 185-210.

Harris, P.A., Coenen, M. and Geor, R.J., 2013. Controversial areas in equine nutrition and feeding management: the editors' views. In: Geor, R.J., Harris, P.A. and Coenen, M. (eds.) Equine clinical and applied nutrition. Elsevier, Amsterdam, the Netherlands, pp. 455-468.

Henneke, D.R., Potter, G.D., Kreider, J.L. and Yeates, B.F., 1983. Relationship between condition score, physical measurements and body-fat percentage in mares. Equine Veterinary Journal 15: 371-372.

Hess, T.M., Kronfeld, D.S., Williams, C.A., Waldron, J.N., GrahamThiers, P., Griewe-Crandell, K., Lopes, M.A. and Harris, P.A., 2005. Effects of oral potassium supplementation of horses during endurance exercise. American Journal of Veterinary Research 66: 466-473.

Hinchcliff, K.W., 1999. Effects of furosemide on athletic performance and exercise-induced pulmonary hemorrhage in horses. Journal of the American Veterinary Medical Association Volume 215: 630-635.

Hintz, H.F., 1983. Nutritional requirements of the exercising horse - a review. In: Snow, D.H., Persson, S.G.B. and Rose, R.J. (eds.) Equine exercise physiology 1. Granta Editions, Cambridge, UK, pp. 275-290.

Hoffman, R.M., Boston, R.C., Stefanovski, D., Kronfeld, D.S. and Harris, P., 2003. Obesity and diet affect glucose dynamics and insulin sensitivity in Thoroughbred geldings. Journal of Animal Science 81: 2333-2342.

Ignatoff, J. and Hintz, H.H., 1980. A survey of feeding practices at two Standardbred racetracks. Feedstuffs, 6 October 1980: 24-25.

Jansson, A. and Dahlborn, K., 1999. Effects of feeding frequency and voluntary salt intake on fluid and electrolyte regulation in athletic horses. Journal of Applied Physiology 86: 1610-1616.

Jansson, A., Johannisson, A. and Kvart, C., 2010. Plasma aldosterone concentration and cardiovascular response to low sodium intake in horses in training. Equine Veterinary Journal 42: 329-334.

Jeffcott, L.B. and Kohn, C.W., 1999. Contributions of equine exercise physiology research to the success of the 1996 Equestrian Olympic Games: a review. Equine Veterinary Journal Suppl. 30: 347-355.

Jeffcott, L.B., Field, J.R., McLean, J.G. and O'Dea, K., 1986. Glucose tolerance and insulin sensitivity in ponies and Standardbred horses. Equine Veterinary Journal 18: 97-101.
Kearns, C.F., McKeever, K.H., Kumagai, K. and Abe, T., 2002. Fat-free mass is related to one-mile race performance in elite standardbred horses. Veterinary Journal 163: 260-266.

Kreider, R.B., Miriel, V. and Bertun, E., 1993. Amino acid supplementation and exercise performance. Analysis of the proposed ergogenic value. Sports Medicine Volume 16: 190-209.

Kronfeld, D.S. and Harris, P.A., 2003. Equine grain-associated disorders (EGAD). Compendium Veterinary Practitioner 25: 974-982.

Lacombe, V., Hinchcliff, K.W., Geor, R.J. and Lauderdale, M.A., 1999. Exercise that induces substantial muscle glycogen depletion impairs subsequent anaerobic capacity. Equine Veterinary Journal Suppl. 30: 293-297.

Lacombe, V.A., Hinchcliff, K.W., Geor, R.J. and Baskin, C.R., 2001. Muscle glycogen depletion and subsequent replenishment affect anaerobic capacity of horses. Journal of Applied Physiology 91: 1782-1790.

Lawrence, L., Jackson, S., Kline, K., Moser, L., Powell, D. and Biel, M., 1992. Observations on body weight and condition of horses in a 150-mile endurance ride. Journal of Equine Veterinary Science 12: 320-324.

Lawrence, L.M., Williams, J., Soderholm, L.V., Roberts, A.M. and Hintz, H.F., 1995. Effect of feeding state on the response of horses to repeated bouts of intense exercise. Equine Veterinary Journal 27: 27-30.

Leleu, C. and Cotrel, C., 2006. Body composition in young Standardbreds in training: relationships to body condition score, physiological and locomotor variables during exercise. Equine Veterinary Journal 38: 98-101.

Leleu, C., Cotrel, C. and Courouce-Malblanc, A., 2005. Relationships between physiological variables and race performance in French standardbred trotters. Veterinary Record 156: 339-342.

Lim, A.S., 1980. Body weight and performance in racehorses. In: Proceedings of the $4^{\text {th }}$ international conference on control of the use of drugs in racehorses. Melbourne, Australia, pp. 93-94.

Lindberg, J.E. and Palmgren-Karlsson, C., 2001. Effect of partial replacement of oats with sugar beet pulp and maize oil on nutrient utilisation in horses. Equine Veterinary Journal 336: 585-590.

Lindholm, A. and Phiel, K., 1974. Fibre composition, enzyme activity and concentrations of metabolites and electrolytes in muscles of standardbred horses. Acta Veterinaria Scandinavica 15: 287-309.

Lindner, A. and Gansen, S., 1995. Feeding of trotting racehorses in Germany: a survey among applicants for a trainer's license. Veterinary Clinical Nutrition 2: 29-35.

Lindner, A., Schmidt, M. and Meyer, H., 1983. Investigations on sodium metabolism in exercised Shetland ponies fed a diet marginal in sodium. In: Snow, D.H., Persson, S.G.B. and Rose, R.J. (eds.) Equine exercise physiology 1. Granta Editions, Cambridge, UK, pp. 310-318.

Meyer, H., 1987. Nutrition of the equine athlete. In: Gillespie, J.R. and Robinson, N.E. (eds.) Equine exercise physiology 2. ICEEP Publications, Davis, CA, USA, pp. 644-673.

Morifuji, M., Sakai, K., Sanbongi, C. and Sugiura, K., 2005. Dietary whey protein increases liver and skeletal muscle glycogen levels in exercise-trained rats. British Journal of Nutrition 93: 439-445. 
Muhonen, S., Lindberg, J.E., Bertilsson, J. and Jansson, A. 2009. Effects on fluid balance, digestion and exercise response in Standardbred horses feed silage, haylage and hay. Comparative Exercise Physiology 5: 133-142.

Mullen, P.A., Hopes, R. and Sewell, J., 1979. The biochemistry, haematology, nutrition, and racing performance of two year old thoroughbreds throughout their training and racing season. Veterinary Record 104: 90-95.

Nash, R. and Hintz, H.F., 1981. How much do you feed your racehorse? Hoof beats, September 1981: 140-141.

National Research Council (NRC), 1978. Nutrient requirements of horses. National Academic Press, Washington, DC, USA.

National Research Council (NRC), 2007. Nutrient requirements of horses $\left(6^{\text {th }}\right.$ rev. Ed.) National Academic Press, Washington, DC, USA.

Nyman, S., Jansson, A., Dahlborn, K. and Lindholm, A., 1996. Strategies for voluntary rehydration in horses during endurance exercise. Equine Veterinary Journal Suppl. 21: 99-106.

Oldham, S.L., Potter, G.D., Evans, J.W., Smith, S.B., Taylor, T.S. and Barnes, W.S., 1990. Storage and mobilization of muscle glycogen in exercising horses fed a fat-supplemented diet. Journal of Equine Veterinary Science 10: 353-355, 358-359.

Pagan, J.D. and Harris, P.A. 1999. The effects of timing and amount of forage and grain on exercise response in thoroughbred horses. Equine Veterinary Journal Suppl. 30: 451-457.

Pagan, J.D., 1997. Measuring the digestible energy content of horse feeds. In: Proceedings of the KER equine nutrition conference, Lexington, KY, USA, pp. 51-53. Available at: http://www.ker.com/ library/advances/107.pdf.

Pagan, J.D., Geor, R.J., Harris, P.A., Hoekstra, K., Gardner, S., Hudson, C. and Prince, A., 2002. Effects of fat adaptation on glucose kinetics and substrate oxidation during low-intensity exercise. Equine Veterinary Journal Suppl.34: 33-38.

Palmgren Karlsson, C., Lindberg, J.E., Jansson, A. and EssénGustavsson, B., 2002. Effect of molassed sugar beet pulp on nutrient utilisation and metabolic parameters during exercise. Equine Veterinary Journal Suppl. 34: 44-49.

Reaven, G.M., 1988. Role of insulin resistance in human disease. Diabetes 37: 1595-1607.

Redbo, I., Redbo-Torstensson, P., Odberg, F.O., Hedendahl, A. and Holm, J., 1998. Factors affecting behavioural disturbances in racehorses. Animal Science 66: 475-481.

Rice, O., Geor, R., Harris, P., Hoekstra, K., Gardner, S. and Pagan, J. 2001. Effects of restricted hay intake on body weight and metabolic responses to high intensity exercise in thoroughbred horses. In: Proceedings of equine nutrition and physiology society, Lexington, KE, USA, pp. 273-279.

Romanowski, K., Muller, A.M., Vernunft, A., Kanitz, W., Kienzle, E., Furll, M., Harris, P.A. and Zeyner, A., 2009. Effects of oral sodium chloride load on acid base and mineral balance of exercised horses. In: Proceedings of the $13^{\text {th }}$ congress of ESVCN, October, Oristano, Italy, p. 111.

Sarafidis, P.A. and Nilsson, P.M., 2006. The metabolic syndrome: a glance at its history. Hypertension 24: 621-626.
Schryver, H.F., Parker, M.T, Daniluk, P.D, Pagan, K.I., Williams, J., Soderholm, L.V. and Hintz, H.F., 1987. Salt consumption and the effect of salt on mineral metabolism in the horse. Cornell Veterinarian 77: 122-131.

Slade, L.M., Lewis, L.D., Quinn, C.R. and Chandler, M.L., 1975. Nutritional adaptations of horses for endurance performance. In: Proceedings of equine nutrition and physiology symposium, Pomona, CA, USA, p. 114.

Snow, D.H., Baxter, P. and Rose, R.J., 1981. Muscle fibre composition and glycogen depletion in horses competing in an endurance ride. Veterinary Record 108: 374-378.

Snow, D.H., Harris, R.C., Harman, J.C. and Marlin, D.J., 1987. Glycogen repletion following different diets. In: Gillespie, J.R. and Robinson, N.E. (eds.) Equine exercise physiology 2, ICEEP Publications, Davis, CA, USA, pp. 701-710.

Southwood, L.L., Evans, D.L., Bryden, W.L. and Rose, R.J., 1993. Nutrient intake of horses in Thoroughbred and Standardbred stables. Australian Veterinary Journal 70: 164-168.

Stark, M. and Collman, C., 2012. Hästen i centrum-Hästens roll och möjligheter som samhällsresurs. Kungliga Skogs- och Lantbruksbruksakademiens Tidskrift 151: 8.

Stull, C.L. and Rodiek, A.V., 1995. Stress and glycemic responses to postprandial interval and feed components in exercising horses. Journal of Equine Veterinary Science 15: 382-386.

Thorland, W.G., Johnson, G.O., Cisar, C.J., Housh, T.J. and Tharp, G.D., 1987. Strength and anaerobic responses of elite young female sprint and distance runners. Medicine and Science in Sports and Exercise 19: 56-61.

Vigre, H., Chriél, M., Hesselholt, M., Falk-Rønne, J. and Kjaer Ersbøll, A., 2002. Risk factors for the hazard of lameness in Danish Standardbred trotters. Preventive Veterinary Medicine 56: 105-117. Waller, A.P. and Lindinger, M.I., 2010. Nutritional aspects of post exercise skeletal muscle glycogen synthesis in horses: a comparative review. Equine Veterinary Journal 42: 3274-281.

Waller, A.P., Geor, R.J., Spriet, L.L., Heigenhauser, G.J.F. and Lindinger, M.I., 2009. Oral acetate supplementation after prolonged moderate intensity exercise enhances early muscle glycogen resynthesis in horses. Experimental Physiology 94: 888-898.

Williams, C.A., Kronfeld, D.S., Hess, T.M., Waldron, J.E, Crandell, K.M., Saker, K.E., Hoffman, R.M. and Harris, P., 2004. Antioxidant supplementation and subsequent oxidative stress of horses during an $80 \mathrm{~km}$ endurance race. Journal of Animal Science 82: 588-594.

Williamson, A., Rogers, C.W. and Firth, E.C., 2007. A survey of feeding, management and faecal $\mathrm{pH}$ of Thoroughbred racehorses in the North Island of New Zealand. New Zealand Veterinary Journal 55: 337-341.

Winter, L., 1980. A survey of feeding practices at two thoroughbred racetracks. Thesis. Cornell University, Ithaca, NY, USA.

Zmija, G., 1991. Futterungspraxis bei galopp- und Trabennpferden. Dissertation. Institut fur Tierernährung der Tierärztlichen Hochschule, Hannover, Germany. 